\title{
Engaging the Community through Science Nights: An Elementary School Case Study
}

\author{
Rosemary A. Riggs' ${ }^{1}$, Courtney J. White', Tracie Kuenzi², Mika Sifuentes', Shaunna R. Garner², Ramon A. Gleason², \\ Jennifer Lee ${ }^{3}$, Christine C. Ziese ${ }^{4}$, Juliana Berry ${ }^{5}$, Maricela A. Garza', Debborah Vann², Chase W. Fordtran', Kandi K. \\ Grimes ${ }^{1}$, Jodie Gray ${ }^{7}$, and Teresa M. Evans ${ }^{1}$
}

\begin{abstract}
${ }^{1}$ Department of Pharmacology, University of Texas Health San Antonio; ${ }^{2}$ Northeast Independent School District; ${ }^{3}$ Saint Mary's Hall; ${ }^{4}$ New Braunfels Independent School District; ${ }^{5} \mathrm{Judson}$ Independent School District; ${ }^{\circ}$ Incarnate Word High School; ${ }^{7}$ Department of Radiology, University of Texas Health San Antonio
\end{abstract}

Keywords: STEM, parental engagement, hands-on activities, teacher empowerment, K-12

Publication Date: April 16, 2019

DOI: https://doi.org/10.15695/jstem/v2i1.06

\begin{abstract}
Parental involvement increases K-12 student interest in STEM careers; however, when parents lack confidence in STEM content, or language and cultural barriers exist, parental engagement decreases. The Teacher Enrichment Initiatives (TEI) collects annual teacher feedback regarding the level of parental involvement with students during science nights, which laid the foundation for teachers to develop a science night training. Using qualitative methods, this single-case study follows elementary teachers who participated in the TEI science night training as they implement a Science Night program at a majority-minority elementary school. Data were gathered by TEI staff during the inaugural and third year of the Science Night program showing an increase in attendance from 700 (2016) to 800 (2018) and an increase in parental engagement with their student in STEM-related activities from 46\% (2016) to 62\% (2018). The data and follow-up summary were used by the case study school teachers to write and secure grants to support an annual Science Night program. This case study suggests Science Nights can be a mechanism to promote parental engagement with their student in hands-on STEM activities. Further, this case study suggests teacher feedback and inclusion in developing a science night model is central to successful implementation of a science night program.
\end{abstract}

\section{INTRODUCTION}

K-12 science, technology, engineering, and math (STEM) education is essential to the future sustainability of the STEM workforce. In addition to a student's formal education in a school setting, parental engagement can have a profound impact on their student's education and eventual pursuit of a career in a STEM field (Mitchell et al., 2008; Nugent et al., 2015). Research suggests students who engage directly with parents in school-related activities exhibit positive attitudes and behaviors at school, which is associated with high academic achievement (Park et al., 2017; McNeal, 2014). This is especially important among populations who are historically underrepresented in STEM, such as nonwhite ethnic minorities, women, and those from low socioeconomic backgrounds (Fouad and Santana, 2017; Hernandez et al., 2016).

When parents lack confidence in their own STEM-related knowledge, they exhibit a reluctance to engage with their student in school-related STEM events (Shymansky et al., 2000). Reluctance to engage with students is not always related to parent knowledge. It can be culturally motivated.
For example, the Latino culture has a high regard for teachers and due to the deep respect for teachers, Latino parents are reluctant to engage unless specifically invited by the teacher or school (Hernandez et al., 2016; Ramirez, 2003). The range of variables that adversely impact parental engagement with their student are diverse, but the end result is the same: student achievement is negatively affected (Knapp et al., 2016; McCrory Calarco, 2014).

Parents who wish to deepen their STEM knowledge can do so through community resources such as museums. Museums provide informal education venues where parents can engage with their student in STEM-related activities while expanding their own understanding of STEM fields. These vital community organizations differ from formal educational institutions in the level of choice participants have in their learning experiences (Harlow, 2012). Static and interactive, hands-on exhibits can be designed to promote interactions between parents and their student. Unconstrained by state educational standards, museums provide a variety of experiences that appeal to a wide range of interests and showcase 
the connection between science and their world (Yanowitz and Hahn-Vaughn, 2016; Birmingham, 2016).

However, studies indicate diverse members of the community may not feel a sense of belonging at museums due to limited representation of their culture within museum exhibits or activities (Dawson, 2014; Ash and Lombana, 2013). Birmingham (2016) posits museums interpret science through the lens of the dominant culture. According to Ash and Lombana (2013) non-dominant cultures view museum visits as an opportunity for quality family time. With an emphasis on family time, the lack of diverse cultural representation can lead to a decreased desire to attend museums in favor of other activities more connected to their culture (Birmingham, 2016). When museums reflect the diversity of their community, they build bridges of inclusion (Ash and Lombana, 2013). Based on the aforementioned studies, museums that take into consideration the diverse nature of the community and reflect this diversity in exhibits have greater connections with all cultures within the community.

Another informal approach to science education is participation in science fairs, which provide students the opportunity to explore and showcase their knowledge about a specific science concept. As an informal science venue, science fair projects do not need to align with state educational standards, allowing students to explore STEM interests outside the scope of the classroom (Schmidt and Kelter, 2017; Grinnell et al., 2017). Science fairs emphasize individual student participation and, as a mechanism to promote parental engagement, this structure may have limitations.

Science fair formats may also limit parental engagement with their student. Formats include voluntary participation as part of an extra-curricular event or compulsory student participation where students receive a grade for their project. Science fairs that apply a voluntary format can create opportunity for parents to engage with their student throughout the science fair process. However, when a science fair project is tied to a grade, parental engagement is discouraged (Schmidt and Kelter, 2017). Studies have found that high school students had a negative response to science fairs when participation was a compulsory component of a science class (Grinnell et al., 2018; Schmidt and Kelter, 2017). Disinterested students exhibited negative attitudes when science fairs are compulsory, resulting in poorly executed science fair projects which adversely impact their academic success (Grinnell et al., 2018).

When surveyed, Grinnell et al. (2017) found that $47 \%$ of high school students indicated receiving assistance with science fair projects from parents. However, given science fairs are intended to showcase individual student achievement, the question remains as to an acceptable level of parental engagement. Tortop (2013) found the majority of parents had a negative view of science fairs or were simply indifferent to them. As a model to promote parent and student engagement in STEM activities, the structure of science fairs may inherently limit parent engagement with their student.

Engaging Families through Science Nights. There is evidence that parents who engage with their students in STEM-related activities, both in and out of school lay a foundation that can have a life-long impact on their student's interest in STEM careers (Mitchell et al., 2008; Nugent et al., 2015). Schools provide science education opportunities for students, but there is a need to engage the entire family in a guided, yet flexible, setting. One approach to address this need is through the Science Night model, a semi-formal model that encourages parent engagement in a supportive environment. Science Nights are family-accessible events that take place at local schools outside normal work/school hours to foster positive science interactions for both students and parents. Outreach programs, such as science nights, have a positive effect on the intended audience "regardless of gender, language and ability" (Shanahan et al., 2011). As a school-sponsored event, the hands-on activities translate classroom science content into conversations and activities that can be replicated at home (Hernandez et al., 2016), providing students the opportunity to share their knowledge with parents in a reciprocal learning relationship. Science nights expose students and families to resources and materials that may be unavailable in the classroom and introduce community members who share their expertise in STEM-related fields and provide information about STEM careers (Shanahan et al., 2011).

Science Nights by Teacher Request. The Teacher Enrichment Initiatives (TEI), housed at the University of Texas Health San Antonio (UTHSA), creates programs based on teacher feedback to empower local teachers through various programs, such as the Teacher Enrichment Leadership Academy (TELA). The TELA is a teacher-led organization of K-12 STEM teachers. Collaborations between the TEI, UTHSA, and the teacher leaders of TELA have resulted in a comprehensive program to support K-12 teachers across the San Antonio area. One such program is an annual one-day conference for K-12 STEM teachers. The conference provides professional development workshops and is the primary source for the TEI to gather feedback from area teachers.

Over 140 teachers attended the 2012 conference. On the conference evaluation, teachers provided comments and professional development requests. Included in the requests were teachers asking for support to plan and execute science nights at their schools. Similar requests were included in the evaluations for the 2013, 2014, and 2015 conferences. After reviewing the requests, two themes emerged: teachers believed science nights would be beneficial to students and improve parent involvement. 
Teacher Designed Science Night Model. As previously stated, science nights are an effective means to engage parents, students, and community members with science. Of the teachers surveyed between 2012 and 2015, only 39\% $(\mathrm{N}=528)$ stated science nights were offered at their schools. In 2014 and 2015, we asked teachers about their ability to take on a leadership role to organize a science night at their school. Of the 233 teachers who responded, 55\% indicated they did not have sufficient knowledge and tools to organize a science night. Teachers reported their schools or districts have made science nights an initiative, yet the majority of teachers surveyed believe they lack the skills to implement such a program. These data informed the decision to create a science night training program where teachers collaborate to empower colleagues with the knowledge and tools necessary to implement a science night.

Developing the Model. The TEI and TELA missions include empowering K-12 teachers through professional development programs. Guided by the TEI Educational Development Specialist (EDS), a certified secondary science teacher with a master's degree in curriculum and instruction, the TELA teacher leaders researched various science night models and conducted literature reviews pertaining to science night planning. The teacher leaders identified three recurring issues: setting objectives to meet student, school, or community needs, recruiting and sustaining a planning committee, and securing event participants.

Using these three issues as guides, the TELA teacher leaders reflected on their own science night experiences. They reviewed four-years of teacher feedback representing different grade levels and content areas from over 30 independent school districts, parochial schools, and private education academies. Feedback was also provided by teachers who serve specific demographics, such as special education and English as a Second Language (ESL). The TELA teacher leaders determined the feedback aligned with the issues identified within the literature: setting objectives to meet student, school, or community needs, recruiting and sustaining a planning committee, and securing event participants. With this information, the teacher leaders developed the training module and support tools resulting in a TEI Science Night Training module grounded in literature that reflects a spectrum of teacher voices.

Science Night Training with Support Tools. The TEI Science Night Training module was presented as a threehour professional development workshop. The training aligns with the TEI Needs Assessment, engaging teachers in discussion as they work through the tool. In developing the Needs Assessment, teacher feedback indicated science nights should have a defined purpose to address the needs of the students, school or community. Possible purposes could include exploring STEM careers, addressing community health issues, or targeting specific education standards. The TEI Needs Assessment provides teachers with guiding questions that promote reflection and discussion to determine the objectives and outcomes that will best address their goals for a science night. It provides information to address general logistics questions such as how and from whom to obtain permission, securing a date and location, and suggestions to engage community support.

During the training, teachers participate in "elbow-partner" discussions, facilitated small group discussions, and share-outs. As part of the training, teachers engage with hands-on science night activities designed by the TEI EDS and TELA teacher leaders. This part of the training exposes teachers to a variety of activities to meet a variety of event objectives, helps teachers better understand spatial requirements of activities and plan for activity requirements, such as electricity and WiFi. After completing the TEI Assessment, the training reviews the TEI Planning Checklist, which guides teachers through the process of forming a planning committee, delegating duties, and setting a timeline to assist in planning the event.

In this qualitative, single case study, we followed the development and growth of a Science Night program at a local elementary school over three school-years: 2015-2016, 2016-2017, and 2017-2018. The school did not have a history of hosting a science night and the teachers, who completed the Science Night Training module, had no experience in planning a science night. Through this case study, we sought to better understand 1) how the TEI Science Night Training and tools are applied by teachers and 2) how the Science Night model affects interactions between parents and students during the event.

\section{METHODS}

Rationale for a Single Case Study Design. We chose to conduct a qualitative single case study design due to the complexity of controlling variables in an educational setting (Tincani and Travers, 2017) and the methodology implemented to collect data (Baxter and Jack, 2008). According to Creswell and Poth (2018), a single case study design establishes boundaries on the study to better focus on gaining understanding of our study questions: how the Science Night Training and tools are applied by teachers and how the Science Night model affects interactions between parents and students during the event.

Student Subjects and School Environment. The case study was conducted at a public school with grades K through 5. In the 2016-2017 academic year, the school had an enrollment of 511 students with a majority-Hispanic $(65.8 \%)$ subpopulation. As shown in Table 1, additional subpopulations 
of students included economically disadvantaged (39.1\%), English language learners (5.5\%), and at-risk (16.0\%), all of which were lower than the school district and state levels. Overall, the school met standards in the State of Texas Assessments of Academic Readiness (STAAR) standardized testing program. The 5th grade STAAR Science scores for 2016 and 2017 were $72 \%$ and $68 \%$ at approaching grade level and above, respectively, which were similar to district and state levels.

Table 1. Case Study School Student Profile

\begin{tabular}{lccc}
\hline Student Information & School & District & State \\
\hline Total Student Enrollment & 511 & 62,217 & $5,343,834$ \\
\hline Ethnic Distribution & & & \\
\hline African American & $2.20 \%$ & $7.30 \%$ & $12.60 \%$ \\
Hispanic & $65.80 \%$ & $58.90 \%$ & $52.40 \%$ \\
White & $26.80 \%$ & $26.20 \%$ & $28.10 \%$ \\
Other & $5.30 \%$ & $7.50 \%$ & $6.90 \%$ \\
Economically Disadvantaged & $39.10 \%$ & $46.60 \%$ & $59.00 \%$ \\
English Language Learners & $5.50 \%$ & $11.70 \%$ & $18.90 \%$ \\
At-Risk & $16.00 \%$ & $38.30 \%$ & $50.30 \%$ \\
\hline
\end{tabular}

$5^{\text {th }}$ Grade Science State Standardized Test Performance

Approaches Grade Level or Above

\begin{tabular}{llll}
\hline 2016 & $72 \%$ & $77 \%$ & $74 \%$ \\
2017 & $68 \%$ & $76 \%$ & $74 \%$ \\
\hline
\end{tabular}

Note: Economically disadvantaged (eligible for free or reduced lunch); English Language Learners (students whose primary language is not English); At-Risk (students at higher risk of dropping out of school due to extenuating home or personal situations or failure to progress academically)

Interventions. In this case study, interventions were conducted during the 2015-2016 and 2017-2018 school years and consisted of Science Night Training, access to planning tools, and regular interaction with the TEI EDS. During 2016-2017, teachers had access to the planning tools, but no additional training or regular interactions with the EDS. For the 2017-2018 school year, case study teachers participated in an updated Science Night Training, and resumed regular interactions with the EDS. During the 2015-2016 and 2017-2018 science nights, an observation protocol was implemented at the case study elementary school. Teachers received a summary of data obtained through the observation protocol.

2015-2016 Interventions. In the summer of 2015, the case study teachers met twice with the TEI EDS. During the first meeting, the teachers shared their completed Needs Assessment, with objective one identifying specific state science standards they wished to target at the science night and a second objective to provide activities to increase parent engagement with students. During the second meeting with the
EDS, the Planning Guide was used to set event and committee goals, including targeted completion dates to secure permissions, finalize location and delegating responsibilities to planning committee members. Two more meetings occurred in October and November 2015. The teachers created committee meeting agendas and facilitated the meetings with limited input from the EDS. These meetings included the planning committee, where individuals reported on the progress of their assigned duties, including advertising, donations from local businesses, community exhibitors, and school support.

Science Night Participation Protocol. During the 20152016 Science Night, observers from the TELA and TEI staff evaluated 12 activities, selected at random, presented by teachers or community members. The observation protocol was developed in collaboration with the TEI staff, TELA teacher leaders, and program evaluators. Activities were observed for 15-minutes, recording subject participation level in four categories: on-task as a family, on-task students only, on-task parent only, no participation/off task. Observers included a description of the activity, indicating if the purpose of the activity was clear and identifying the level of engagement between the activity facilitator and participants. Observers also recorded additional information such as activity connection to state standards and STEM career connections. The data were evaluated, and a summary of the findings was provided to the case study teachers. The EDS reviewed the summary with the teachers focusing on the two objectives: activities to target specific state science standards and activities to increase parent engagement with students. The data revealed the observed teacher facilitators could not explain the science behind their activity. It should be noted the elementary teachers facilitating these activities are not science certified. Regarding the objective to increase parent engagement with students, $46 \%$ of the observed activities showed parents interacting with their student on the activity.

2017-2018 Interventions. Interventions resumed in the summer of 2017 and were similar to interventions conducted during 2015-2016 with a noted exception: the science night objectives for the case study school had changed. Based on feedback from 2015-2016, the objectives evolved: 1) teacher facilitators will be able to explain the science of the activity and 2) increase parent engagement with students at activities. The same two teachers attended an updated Science Night Training module and continued to use the Science Night Planning tools. Additionally, they again met with the EDS, two times during the summer of 2017 and two times in the fall of 2017 while planning for their 2017-2018 science night. To address objective one, the teachers previewed all teacher-facilitated activities, seeking guidance from the EDS as to the science connections. To address objective two, the 
committee also critically evaluated all potential activities to increase the number of interactive offerings to encourage increased parental engagement with students. The observation protocol was again implemented at the 2017-2018 Science Night. The data were evaluated, and a summary of the findings was provided to the teachers.

\section{RESULTS}

Teacher Feedback to Guide Program Development. Over a four-year period, 2015 through 2018, we gathered anonymous feedback from a convenience sample of teachers from multiple school districts. Using a 4-point Likert scale (anchored at $1=$ Strongly Disagree to $4=$ Strongly Agree) teachers responded to eight questions pertaining directly to Science Nights. A total of 532 teachers responded as shown in Table 2 . In the sample of convenience surveys given to attendees at the TEI conference, $39 \%(208 / 528)$ of respondents reported that their school currently offered Science Nights. Ninety six percent $(514 / 532)$ of respondents agreed or strongly agreed that a Science Night at their school would benefit their students, while $91 \%$ (480/526) of respondents agreed or strongly agreed that a Science Night at their school would improve parental involvement. Lastly, 79\% (408/519) of respondents agreed or strongly agreed that teachers at their school would be willing to participate in a Science Night event.

Comparing 2015 to 2018, there was a $21 \%$ increase in teachers who strongly agree a science night would benefit their students. Over the same four-year period, there was a $31 \%$ increase in the number of teachers who strongly agreed parental involvement would be improved by science nights. Teacher feedback gathered at the TEI conferences identified specific needs of area teachers regarding the planning and implementation of a Science Night event and was used to inform the content of the TEI Science Night training program.

Results of Activity Evaluations. During Science Nights in 2016 and 2018, observers from the TEI staff evaluated the Science Night activities and participation by students and their families using the observation protocol, observing 12 activities in 2016 and 17 activities in 2018. As shown in Table 3 , there was a clearly defined purpose in $66 \%(8 / 12)$ and $94 \%(16 / 17)$ of the observed activities in 2016 and 2018, respectively. In both years, nearly all observed activities were hands-on (2016: 100\% [12/12] and 2018: 95\% [16/17]). The majority of activities in both years were designed to engage a mixed audience of elementary students and their parents (66\% [8/12] and 53\% [9/17], respectively). Most of the activity facilitators interacted with the participants through questions related to the activity (83\% [10/12] and $76 \%$ [13/17], respectively). A lesser majority (64\% [7/12] and $65 \%$ [11/17], respectively) connected the activity topic to real-world examples. In 2016, the facilitators at 5\% (3/12) of the observed activities shared something about their own work or studies with their audience. This increased to $47 \%$ $(8 / 17)$ in 2018.

Increased Engagement with Science Night Activities. Participant engagement was assessed in a subset of activities over a 15-minute observation period. As shown in Figure 1, in 2016182 families were observed at the subset of 12 activities. Across the subset of 12 activities, 46\% (83/182) of participants were on task as a family, $49 \%(90 / 182)$ were on task as students only, and $0 \%(1 / 182)$ were on task as parents only. There were $5 \%(9 / 182)$ of families off task during the observation period. In 2018, observations were collected of 146 families at 12 activities. At the activities, 62\% (91/146) of participants were on task as a family. There were $31 \%$ (45/146) of students only on task, and there were no families in which only the parents were on task. Seven percent $(10 / 146)$ of families were observed as off task. The $35 \%$ increase in family engagement from 2016 to 2018 correlates to the $37 \%$ decrease in student only participation from 2016 to 2018 .

Qualitative Outcomes. Descriptive outcomes were collected from volunteers and TELA observers after each event. In their observations, the activities in which the facilitators

Table 2. TEI Conference Evaluation Outcomes: Teacher Feedback Regarding Science Night

\begin{tabular}{|c|c|c|c|c|c|}
\hline Conference Evaluations: Science Night Questions & Scale & 2015 & 2016 & 2017 & 2018 \\
\hline \multirow{2}{*}{ Q1: A science night at my school would benefit students. } & Agree & $\begin{array}{c}60 \% \\
(\mathrm{~N}=102)\end{array}$ & $\begin{array}{c}45 \% \\
(\mathrm{~N}=56)\end{array}$ & $\begin{array}{c}58 \% \\
(\mathrm{~N}=72)\end{array}$ & $\begin{array}{c}47 \% \\
(\mathrm{~N}=53)\end{array}$ \\
\hline & $\begin{array}{l}\text { Strongly } \\
\text { Agree }\end{array}$ & $\begin{array}{c}37 \% \\
(\mathrm{~N}=64)\end{array}$ & $\begin{array}{c}52 \% \\
(\mathrm{~N}=65)\end{array}$ & $\begin{array}{c}39 \% \\
(\mathrm{~N}=48)\end{array}$ & $\begin{array}{c}45 \% \\
(\mathrm{~N}=51)\end{array}$ \\
\hline \multirow{2}{*}{ Q2: A science night at my school would improve parental involvement. } & Agree & $\begin{array}{c}60 \% \\
(\mathrm{~N}=101)\end{array}$ & $\begin{array}{c}41 \% \\
(\mathrm{~N}=51)\end{array}$ & $\begin{array}{c}5 \% \\
(\mathrm{~N}=68)\end{array}$ & $\begin{array}{c}48 \% \\
(\mathrm{~N}=53)\end{array}$ \\
\hline & $\begin{array}{l}\text { Strongly } \\
\text { Agree }\end{array}$ & $\begin{array}{c}32 \% \\
(\mathrm{~N}=54)\end{array}$ & $\begin{array}{c}51 \% \\
(\mathrm{~N}=63)\end{array}$ & $\begin{array}{c}36 \% \\
(\mathrm{~N}=44)\end{array}$ & $\begin{array}{c}42 \% \\
(\mathrm{~N}=46)\end{array}$ \\
\hline
\end{tabular}

Note: The number of conference evaluation respondents $(N)$ varied year to year $(2015, N=171 ; 2016, N=124 ; 2017, N=124 ; 2018, N=113)$ for a total of 532 respondents. 
Table 3. Observation Protocol Outcomes

\begin{tabular}{|c|c|c|}
\hline Activities Observed & $\begin{array}{c}2016 \\
(\mathrm{~N}=12)\end{array}$ & $\begin{array}{c}2018 \\
(\mathrm{~N}=17)\end{array}$ \\
\hline \multicolumn{3}{|l|}{ Activity } \\
\hline Clearly identified purpose & $8(66 \%)$ & $16(94 \%)$ \\
\hline Involved a hands-on activity & $12(100 \%)$ & $16(94 \%)$ \\
\hline Included a demonstration & $8(66 \%)$ & $8(47 \%)$ \\
\hline \multicolumn{3}{|l|}{ Design } \\
\hline Designed for students & $4(33 \%)$ & $8(47 \%)$ \\
\hline Designed for adults & $0(0 \%)$ & $0(0 \%)$ \\
\hline Designed for both students and adults & $8(66 \%)$ & $9(53 \%)$ \\
\hline \multicolumn{3}{|l|}{ Facilitator } \\
\hline $\begin{array}{l}\text { Engaged the participants with } \\
\text { questions }\end{array}$ & $10(83 \%)$ & $13(76 \%)$ \\
\hline $\begin{array}{l}\text { Connect the topic to a real-world } \\
\text { example }\end{array}$ & $7(64 \%)$ & $11(65 \%)$ \\
\hline $\begin{array}{l}\text { Share something about their } \\
\text { work/studies }\end{array}$ & $3(25 \%)$ & $8(47 \%)$ \\
\hline
\end{tabular}

Figure 1. Comparison of Science Night participation by category from 2016 to 2018. When comparing "on-task as a family", 2016 was $46 \%$ and 2018 was $62 \%$. The "on-task kids only" category saw a decrease from $2016(49 \%)$ to 2018 (31\%). There were minimal to no changes seen for "parents only" and "off task" categories.

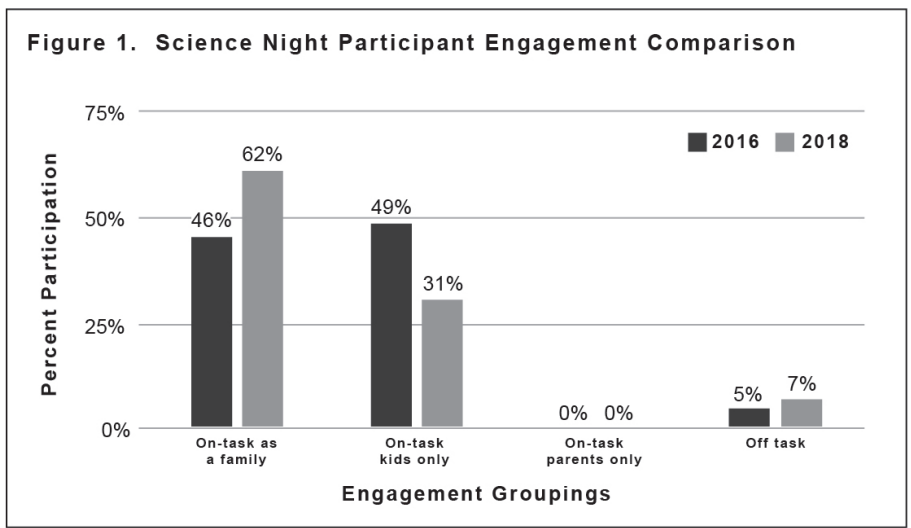

explained the science concepts had longer engagement with students and parents. When there was little explanation of the science concepts or connection of science to the "real-world", participants did not remain at the activity for a sustained period of time. In some instances, the facilitators appeared to be unsure of the science background of the activity, which could be improved by more targeted training during the preparation stage. Questions asked by the facilitator were effective in keeping participants focused; however, to improve future Science Night events, preparatory information from each activity organizer should be gathered to provide adequate support and ensure activity facilitators are confident in the science content and are able to connect activities to STEM careers and state educational standards.
After the 2016 event, the coordinating teachers expressed their belief that the Science Night was a success in engaging students and their families. The lead teacher commented:

Our success from the first science night gave us the confidence to plan our second science night, which was bigger than the first. We used the checklist and needs assessment again in the planning. The timeline that the tools provide is essential to the planning. We had a bigger turnout the second year with some of our parents telling the administration that it is their favorite night of the year.

The data generated by the observation protocol were shared with the Science Night planning committee who presented the data to their administration. The data was used by administration to strengthen teacher annual evaluations, provide evidence of school progress toward meeting community involvement initiatives and secure administrative support for annual Science Nights. The coordinating teachers also submitted and were awarded a grant from the district foundation to support future Science Nights.

Choosing to host the event after school hours on a weekday impacted attendance for the intervention years. The case study teachers involved teachers, administration, and parents in determining the day of the week and times for the Science Night. Considering the size of the student population of 511, the 2016 and 2018 Science Nights had a relatively high estimated attendance, 700 and 800 respectively, as shown in Table 4. During 2016 and 2018, attendees included current students and parents, families that brought younger and older siblings not enrolled at the elementary school, extended family members such as grandparents, and general community members. This high level of engagement by the extended community indicate the time and dates selected to host the Science Nights were convenient to the community. The attendance also indicates the level of importance the community ascribes to the elementary school in this case study.

From 2016 to 2018, there was a marked increase in the number of activities with a clearly defined purpose, increasing from $66 \%$ to $94 \%$, respectively. In both intervention years, the data show a consistent number of hands-on activities, with a majority designed for parent interaction with their student. We also observed an increase in the percentage of activity facilitators who shared STEM-related information

Table 4. Science Night Attendance

\begin{tabular}{lccc}
\hline Attendee Group & $\mathbf{2 0 1 6}$ & $\mathbf{2 0 1 7}$ & $\mathbf{2 0 1 8}$ \\
\hline $\begin{array}{l}\text { Estimated Students/Parents } \\
\text { (provided by school) }\end{array}$ & 700 & 750 & 800 \\
\hline Volunteers & 7 & 7 & 8 \\
\hline TELA Teachers & 11 & 10 & 8 \\
\hline UTHSA Faculty/Students & & & \\
\hline
\end{tabular}


regarding their work or studies, 25\% in 2016 as compared to $47 \%$ in 2018 . This was a deliberate increase, according to the case study teachers, as they incorporated a stronger emphasis on informing students and parents of the types of STEM careers and STEM education programs available at area universities. Their expressed intent was to help students and parents view STEM education as a path toward future career options.

\section{DISCUSSION}

Positive Teacher and School Impact. This case study highlights a science night model developed by teachers for teachers in response to science night support requests from local K-12 educators. In the study, we observed how teachers implemented the science night model as they addressed the unique needs of their community. The study also investigated the effect the model, as applied by the case study teachers, had on the interactions between parents and students. This study provides insight into the positive effective teachers can have on students and parents when empowered to take ownership of developing and implementing a science night program. It also demonstrates how teachers can strengthen the connection between a school and the community it serves through application of the TEI Science Night Model.

In this case study, we report the implementation and outcomes of an annual, single-school, science outreach event recurring from 2016 to 2018 which has now become an annual school and community event. The elementary school in this case study has a student enrollment of 511. It is a majority-minority public school with $66 \%$ of the student population identifying as Hispanic and $40 \%$ of its students classified as economically disadvantaged. As the committee of teachers planned the Science Night, they took into consideration the demographics of their school community. Unlike informal education institutions which can unintentionally create cultural barriers to learning (Birmingham, 2016), the case study teachers were acutely aware of the learning needs of their students and the diverse nature of the local community. The teachers involved in the Science Night were observed addressing students and parents by name, which reinforced the community aspect of the Science Night, demonstrating their rapport with participating parents and students. Direct observation of interactions between the case study teachers and participants indicates the teachers are connected to the community in which they serve.

Training and resources provided by the TEI empowered teachers to initiate and organize Science Nights, which were designed with the goal to facilitate positive parent-student engagement in science. The success of the first Science Night promoted the following response from the coordinating teacher:
Our success from the first Science Night gave us the confidence to plan our second Science Night, which was bigger than the first. We were able to secure grant money to support next year's Science Night. We continue to use the TELA Science Night tools in our planning. The checklist is essential to our success. We had a bigger turnout the second year with some of our parents telling the administration that it is their favorite night of the year.

Case study teachers empowered themselves to assume informal leadership roles on their campus as they planned the Science Night. When teachers are afforded the opportunity to undertake leadership roles of their own choosing, it has positive outcomes for teacher collaborations, student attitudes, and overall school success (Cherkowski, 2018). The success of the Science Night program empowered the coordinating teachers to present a workshop to other area K-12 teachers at the annual TELA 2018 conference. The case study teachers shared their Science Night experiences, provided suggestions regarding community resources, and engaged colleagues in discussions about how to use TELA Science Night tools to help plan a successful event. The case study teachers stressed the importance of the TELA evaluation protocol to obtain data to secure administration support and potential financial resources. This case study lays the foundation for a model program that could have long standing positive impacts on teachers' perceptions of themselves as professional practitioners and on school success (Cherkowski, 2018).

Parental and Community Impact. Science Nights create an informal opportunity for parents to actively engage with their student, which may foster an increase in parental involvement in their student's formal education. According to Hill and Tyson (2009), parental involvement in their student's education declines as students get older. But research show that when parents engage with students in events, such as Science Nights, parental involvement and interest in their student's science education increases (Kaya and Lundeen, 2010). There is also a strong connection between student success, both academically and behaviorally, when parents are actively involved with school events (McNeal, 2014). Providing parents opportunities to participate in hands-on activities with their students encourages interactions beyond organized science events (Mitchell et al., 2008), which may increase parental involvement and communication with the school (Ramirez, 2003). This is especially true for parents from diverse cultures or with language barriers (Valdez and Moineau, 2010; Ramirez, 2003).

The outcomes of our case study suggest the Science Night activities were able to overcome language barriers and provide a culturally inclusive environment as evidenced by engagement by families in the event. Almost half of participants 
were on task as a family in $2016(46 \%)$, which increased to a solid majority in 2018 (62\%). This increase correlates to a decrease in activities only involving students in 2016 (49\%) to 2018 (31\%). The $35 \%$ increase in family engagement from 2016 to 2018 correlates to the $37 \%$ decrease in student only participation from 2016 to 2018 . The activities chosen for Science Night by the case study teachers were primarily hands-on, giving families a sense of agency in forming new, positive experiences in STEM subjects. Activities designed to engage students with their parents also allow for a sense of working together, which frames the students' education as a collaborative effort that can be continued at home (Knapp et al., 2016; McNeal, 2014). Ultimately, Science Night can remove barriers to parent engagement in STEM.

In addition to the formal education a student receives at school, students benefit from educational opportunities outside the classroom (Harlow, 2012; Haden et al., 2014; Nugent et al., 2015). This is especially helpful among students from diverse subpopulations such as found at the case study school. Presenting STEM-related activities in a familiar school setting with families to provide a culturally-sensitive context can give the student a sense of belonging in the sciences (Dawson, 2014).When parents are actively engaged with their student's science education the likelihood that the student will demonstrate an interest in STEM careers is increased (Fouad and Santana, 2016; Hernandez et al., 2016; Nugent et al., 2015; Shanahan et al., 2011). Early and consistent parental involvement becomes even more important for subpopulations that are historically underrepresented in STEM careers (Fouad and Santana, 2016; Hernandez et al., 2016; Shanahan et al., 2011; Valdez and Moineau, 2010; Ramirez, 2003). If we are to increase the number of underrepresented subpopulations in STEM careers, this case study provides evidence that parental engagement is important throughout their student's K-12 education.

Study Limitations and Future Directions. This study is limited as it is an observational case study at a single institution. Our results describe the characteristics and outcomes of Science Nights at two timepoints without a baseline comparison; therefore, the data cannot be used to establish a longitudinal trend or indicate causality. Collection and analysis of awareness or support of STEM careers before and after Science Night were beyond the scope of the present study but could be incorporated into future studies. Future studies are needed to connect parent engagement at Science Night to the pursuit of STEM careers. Additionally, further studies could investigate and identify activities and Science Night formats that are most successful in promoting higher parent involvement.

Additional studies are needed as well to determine the impact of Science Nights on age groups beyond the elementary level. Interest in a STEM field career can wane as stu- dents get older while parent involvement often decreases as students begin to take more advanced science classes in the upper grades (Hill and Tyson, 2009). We anticipate that the positive community response and high levels of parent engagement in this case study of a Science Night program at the local elementary school will support the development of more complex studies to investigate the challenges students and families encounter as students transition from elementary to the secondary level and the effect this has on student interest in STEM-related careers.

We recognize the need to better assess potential, longrange benefits of Science Night participation by parents and students. Having secured permission from school administration, the case study teachers, with the guidance of TEI, have developed a parent exit survey to be administered at future Science Nights. The exit survey asks parents to: 1) identify motivating factors to attend the event, 2) indicate the number of activities that provided parent/student engagement, 3) share something new they learned, and 4) provide feedback to help plan future Science Nights. It is our recommendation for the case study teachers to include the option for parents to provide contact information to participate in follow-up interviews regarding the impact of the Science Night. The goal for TEI is to continue to empower teachers to conduct their own research into the lasting impact of their Science Night program.

Science Night Model. This case study has provided a foundation for a model of a Science Night program based on the positive outcomes achieved at one school as a result of a Science Night training program designed by teachers for teachers. When teachers and schools are provided guidance, Science Nights can be refined to maximize parental engagement and encourage community participation. Creating a science night model starts with teachers. Their feedback and inclusion in the development of the model is central to the successful implementation of the TEI Science Night model. The TEI supported and guided TELA teacher leaders as they reviewed feedback from colleagues and conducted literature reviews about science nights. The teacher leaders incorporated this information into a comprehensive Science Night model that includes training, a planning guide, support tools and evaluation protocols. The TEI Science Night model provides a framework to guide teachers through the planning, implementation, and evaluation of their Science Night program. The model empowers teachers to take ownership of the Science Night program as they customize it to fit the needs of their students and community.

\section{CONCLUSION}

Science Nights are intentionally designed to provide a semi-formal learning environment, where parents and stu- 
dents can engage with science in a low-pressure, enjoyable setting, and interact with teachers and volunteers representing STEM careers. Science Nights can strengthen the connection between teachers and students' families, bridging the gap between the classroom experience and the students' home life. This encourages the inclusion of STEM within the family culture, which can counteract the self-perpetuation of education inequalities among students. A key goal of Science Night is to empower parents to feel capable of engaging their student on STEM topics, as research has suggested that a lack of confidence, or past negative experiences in science, can discourage parents from feeling qualified to become involved in their student's education (Shymansky et al., 2000).

In conclusion, Science Night has emerged as a successful, recurring STEM event that focuses on encouraging parent involvement in their student's education at the elementary level. However, much research is still warranted, in part to better define the role Science Nights play in encouraging STEM career exploration and awareness.

\section{AUTHOR INFORMATION Corresponding Author}

The corresponding author is Teresa M. Evans. Evanstm@ uthscsa.edu

\section{Author Contributions}

The manuscript was written through contributions of all authors. All authors have given approval to the final version of the manuscript.

\section{FUNDING SOURCES}

Funded through the National Institutes of Health Science Education Partnership Award

\section{ACKNOWLEDGMENTS}

This outreach program was made possible through the teacher-led Teacher Enrichment Leadership Academy, which aims to break down barriers to make it easier to host Science Nights at more school locations across Texas. Additionally, this program was supported by the NIGMS SEPA R25GM129182-03 awarded to T. Evans. We would like to thank the founding PI of this program, Michael J. Lichtenstein, MD, MSc, for his unwavering belief in the importance of empowering and supporting teachers. We also thank the amazing area teachers who work tirelessly and selflessly to provide our youth with relevant and up-to-date science education. Finally, we wish to thank the scientists at University of Texas Health San Antonio for volunteering their time and talent to support our community outreach programs.

\section{ABBREVIATIONS}

EDS: Educational Development Specialist; ESL: English as a Second Language; STAAR: State of Texas Assessments of Academic Readiness; STEM: Science, Technology, Engineering, and Math; TEI; Teacher Enrichment Initiatives; TELA: Teacher Enrichment Leadership Academy.

\section{REFERENCES}

Ash, D., and Lombana, J. (2013). Reculturing museums: Working toward diversity in informal settings. Journal of Museum Education, 38(1), 69-80. doi: $10.1080 / 10598650.2013 .11510757$

Baxter, P., and Jack, S. (2008). Qualitative case study methodology: Study design and implementation for novice researchers. The Qualitative Report, 13(4), 544-559.

Birmingham, D. (2016). Disorienting, fun or meaningful: Looking beyond the boundaries of the museum. Cultural Studies of Science Education, 11, 953-958. doi:10.1007/s11422015-9705-5

Cherkowski, S. (2018). Positive teacher leadership: Building mindsets and capacities to grow wellbeing. International Journal of Teacher Leadership, 9(1), 63-78.

Creswell, J.W., and Poth, C.N. (2018). Qualitative Inquiry and Research Design: Choosing Among Five Approaches. Los Angeles, CA: Sage.

Dawson, E. (2014). Not designed for us: How science museums and science centers socially exclude low-income, minority ethnic groups. Science Education 98 (6), 981-1008.

Fouad, N.A., and Santana, M.C. (2017). SCCT and underrepresented populations in STEM fields: Moving the needle. Journal of Career Assessment, 25(1), 24-39. doi: $10.1177 / 1069072716658324$

Grinnell, F., Dalley, S., Shepherd, K., and Reisch, J. (2018). High school science fair: Student opinions regarding whether participation should be required or optional and why. PLoS ONE, 13(8): e0202320. https://doi.org/10.1371/ journal.pone. 0202320

Grinnell, F., Dalley, S., Shepherd, K., and Reisch, J. (2017). High school science fair and research integrity. PLoS ONE, 12(13): e0174252, http://doi.org/10.1371/journal. pone. 0174252

Haden, C.A., Jant, E.A., Hoffman, P.C., Marcus, M., Geddes, J.R., and Gaskins, S. (2014). Supporting family conversations and children's STEM learning in a children's museum. Early Childhood Quarterly, 29, 333-344. 
Harlow, D.B. (2012). The excitement and wonder of teaching science: What pre-service teachers learn from facilitating family science night centers. Journal of Science Teacher Education 23(2), 199-220.

Hernandez, D., Rana, S., Alemdar, M., Rao, A., and Usselman, M. (2016). Latino parents' educational values and STEM beliefs. Journal of Multicultural Education, 10(3), 354-367. doi: 10.1108/JME-12-2015-0042

Hill, N.E., and Tyson, D.F. (2009). Parental involvement in middle school: A meta-analytic assessment of the strategies that promote achievement. Developmental Psychology 45(3).

Kaya, S., and Lundeen, C. (2010). Capturing parents' individual and institutional interest toward involvement in science education. Journal of Science Teacher Education, 21, 825841. doi: 10.1007/s10972-009-9173-4

Kratochwill, T.R., Hitchcock, J., Horner, R.H., Levin, J.R., Odom, S.L., Rindskopf, D.M., and Shandish, W.R. (2010). Single-case designs technical documentation. Retrieved form What Works Clearinghouse website: http://ies.ed.gov/ ncee/wwc/pdf/wwc_scd.pdf.

McCrory Calarco, J. (2014). Coached for the classroom: Parents' cultural transmission and children's reproduction of educational inequalities. American Sociological Review, 79(5), 1015-1037. doi: 10.1177/0003122414546931

NcNeal, R.B. (2014). Parent involvement, academic achievement and the role of student attitudes and behaviors as mediators. Universal Journal of Educational Research, 2(8), 564-576. doi: 10.12189/ujer.2014.020805

Mitchell, S.E., Drobnes, E., Sol Colina-Trujillo, M., and Noel-Storr, J. (2008). NASA family science night: Changing perceptions one family at a time. Advances in Space Research, 42, 1844-1847. doi: 10.1016/j.asr.2008.01.004

Nugent, G., Barker, B., Welch, G., Grandgenett, N., Wu, C.R., and Nelson, C. (2015). A model of factors contributing to STEM learning and career orientation. International Journal of Science Education, 37(7), 1067-1088. doi: 10.1080/09500693.2015.1017863

Ramirez, A.Y.F. (2003). Dismay and disappointment: Parental involvement of Latino immigrant parents. The Urban Review, 35(2), 93-109.

Schmidt, K.M., and Kelter, P. (2017). Science fair: A qualitative study of their impact on student science learning and attitudes toward STEM. Science Educator, 25(2), 126-132.

Shanahan, M., Pedretti, E., DeCoito, I., and Baker, L. (2011). Exploring the responses of underrepresented students in science in an elementary classroom outreach program. School Science and Mathematics, 111(4), 131-142.
Shymansky, J.A., Hand, B.M., and Yore, L.D. (2000). Empowering families in hands-on science programs. School Science and Mathematics, 100(1), 48-56.

Teacher Enrichment Initiatives. (2018). Retrieved from http://teiteachers.org/content/teacher-resources

Texas Education Agency (2018). Texas academic performance report. Retrieved from https://tea.texas.gov.

Tortop, H.S. (2013). Science teacher's views about the science fair at primary education level. Journal of Qualitative Inquiry, 4(2), 36-64. doi: 10.17569/tojqi.24559

Valdez, G., and Moineau, S. (2010). The ESL family science night: A model for culturally sensitive science education pedagogy. International Journal of Whole Schooling, 6(2), 4-18.

Yanowitz, K.L., and Hahs-Vaughn, D.L. (2016). Adult's perceptions of children's science abilities and interest after participating in a family science night. School Science and Mathematics, 116(1), 55-64. 